CLINICAL STUDY

\title{
The role of F-18-fluorodeoxyglucose positron emission tomography in the postoperative evaluation of differentiated thyroid cancer
}

\author{
Ali S Al-Zahrani ${ }^{1}$, Mohei-Eldin M Abouzied ${ }^{2}$, Suzan Abdel Salam ${ }^{1}$, Gamal Mohamed ${ }^{3}$, Ayman Rifai ${ }^{2}$, \\ Abdulaziz Al Sugair ${ }^{2}$ and Tarik Amin ${ }^{4}$ \\ Departments of ${ }^{1}$ Medicine (MBC-46), ${ }^{2}$ Radiology, ${ }^{3}$ Research Centre and ${ }^{4}$ Surgical Oncology, King Faisal Specialist Hospital and Research Centre, \\ PO Box 3354, Riyadh 11211, Saudi Arabia \\ (Correspondence should be addressed to A S Alzahrani; Email: aliz@kfshrc.edu.sa)
}

\begin{abstract}
Objectives: The objective of the study was to compare F-18-fluorodeoxyglucose position emission tomography (FDG-PET) with diagnostic whole body scanning (DxWBS) and post-ablation radioiodine whole body scanning (TxWBS) and to assess its prognostic value in newly diagnosed differentiated thyroid cancer (DTC) patients, hypothesizing that FDG-PET is more likely to disclose locoregional and distant metastases.

Patients and methods: DxWBS and FDG-PET scanning were performed in 26 newly diagnosed DTC patients who underwent thyroidectomy and TxWBS in 24 cases who had radioactive iodine ablation. The results of the FDG-PET scans were correlated with the stage of the disease and the long-term outcome of DTC.

Results: Overall, 18 FDG-PET scans (69.2\%) were positive showing a total of 40 foci while 8 scans (30.8\%) were negative. The corresponding 26 DxWBS were all positive and showed a total of 47 foci. DxWBS and TxWBS showed similar foci in the 24 patients who had ablation therapy. In contrast to the FDG-PET scans that showed uptake of 26 foci $(65 \%)$ outside the thyroid bed, 45 foci $(95.7 \%)$ on DxWBS were in the thyroid bed while 2 foci $(4.3 \%)$ were in cervical lymph nodes and no focus was seen outside the neck area $(P=0.000)$. There was a clear correlation between the FDG-PET results, the stage of the disease and long-term outcome; seven of the eight negative FDG-PET scans were in stage 1 , while all patients with disease higher than stage 1 (six patients) had positive scans. Over a median of 30 months (10-48), seven out of eight patients $(87.5 \%)$ with negative FDG-PET scans were in remission compared with only eight patients $(44.4 \%)$ with positive FDG-PET $(P=0.04)$.

Conclusions: In the postoperative evaluation of DTC, compared with DxWBS and TxWBS, FDG-PET scans are more likely to reveal uptake outside the thyroid bed and to correlate with the stage of the disease and long-term outcome.
\end{abstract}

European Journal of Endocrinology 158 683-689

\section{Introduction}

Differentiated thyroid cancer (DTC) is generally considered a rare malignancy with good prognosis (1). However, its incidence has been increasing over the last decade $(1,2)$. The initial diagnosis depends largely on fine needle aspiration biopsy (3). The classical approach after establishing the cytological diagnosis is to proceed with total or near-total thyroidectomy (4). Following initial surgery, high-dose radioiodine-131 (I-131) is usually administered for thyroid remnant ablation (3-5). The objective of such ablation is to eradicate any residual thyroid tissue that may not have been removed surgically and to improve the accuracy of diagnostic whole body scanning (DxWBS) and serum thyroglobulin ( $\mathrm{Tg}$ ) in the long-term follow-up (5). In addition, such therapy was shown to decrease longterm recurrence and mortality rates (6). Pre-therapy (DxWBS) and/or post-ablation therapy whole body scan (TxWBS) are usually performed. The aims of DxWBS and TxWBS are to define the extent of residual thyroid tissue and locoregional or distant metastases (5). In the presence of residual normal thyroid tissue, there is usually a preferential uptake of radioactive iodine (RAI) by this tissue and local or distant metastatic disease may be missed. F-18-fluorodeoxyglucose position emission tomography (FDG-PET) is a relatively new imaging technique. Its role in DTC has been most consistently demonstrated in the follow-up of patients, especially those with high $\mathrm{Tg}$ and a negative DxWBS (7-15). Its role in the postoperative evaluation of patients with DTC 
has not been studied. In this study, we investigated the potential role of FDG-PET in the immediate postoperative evaluation of patients with DTC. In contrast to RAI, which is most avidly taken up by normal thyroid tissue, the uptake of FDG is more likely to be seen in the more metabolically active malignant tissue rather than in benign tissue (16). Therefore, we hypothesized that FDG-PET may be superior to DxWBS in disclosing lymph nodal or distant metastatic DTC in patients who have had surgery, but have not yet received RAI ablation. Therefore, FDG-PET could potentially play an important role in the initial staging of the disease. Furthermore, since positive FDG-PET scans were found previously to correlate with the prognosis in patients who were treated in the past $(17,18)$, we also aimed to investigate its potential prognostic value in DTC patients who have not yet received RAI, hypothesizing that those patients with positive FDG-PET following the initial surgery are more likely to continue to have persistent disease or develop recurrence or metastases during their follow-up.

\section{Materials and methods}

We performed conventional FDG-PET whole body scanning in 26 consecutive new DTC patients who had thyroid surgery but had not yet received RAI ablation. We compared the FDG-PET scans with DxWBS done in those 26 patients who had both scans. We also compared the FDG-PET scans with TxWBS in those patients who subsequently underwent RAI ablation (24 patients). In addition, we correlated the long-term outcome with the results of FDG-PET in all the 26 patients studied. All patients signed an informed written consent and the study was approved by the institutional review board.

\section{Patients}

We prospectively studied 26 consecutive patients who agreed to participate in the study ( 3 males and 23 females, median age 34 years, range $14-76$ years) in the period between September 2003 and May 2005. Patients who refused to participate in the study, those with uncontrolled diabetes (blood sugar $>8 \mathrm{mmol} / \mathrm{l}$, as high blood sugar may interfere with FDG uptake) and those with other known malignancy or inflammatory conditions were excluded. All patients underwent thyroidectomy at their local hospitals and were subsequently referred to our hospital for further management. After confirming the outside diagnosis of DTC by reviewing the histopathological specimens, L-thyroxine was discontinued for at least 5 weeks and triiodothyronine (cytomel) for at least 2 weeks in preparation for DxWBS, measurement of serum $\mathrm{Tg}$, and FDG-PET scanning. The median $\mathrm{Tg}$ level was $23.9 \mathrm{ng} / \mathrm{dl}$ (range 2.9-2565) and the corresponding median TSH level was $133 \mathrm{U} / \mathrm{l}$ (range, 59.5-501). Tg was measured using the sandwich technique with electrochemiluminescence immunoassay (Cobas, Roche Diagnostics $\mathrm{GmbH}$, D-68298 Mannheim) with $0.1 \mathrm{ng} / \mathrm{ml}$ lower limit of detection, $1.4-78 \mathrm{ng} / \mathrm{ml}$ normal range in healthy subjects and 1.7 and $2.7 \%$ within-run and total coefficients of variation respectively. Overall, 23 cases underwent total or near-total thyroidectomy and unilateral (16 cases) or bilateral ( 7 cases) modified neck dissection, and three patients underwent total or near-total thyroidectomy without neck dissection. The final histopathological examination showed classic PTC in 24 patients, tall cell variant PTC in 1 patient and minimally invasive follicular thyroid cancer in 1 patient. Of the 23 patients who underwent unilateral or bilateral neck dissection, 16 patients $(69.6 \%)$ had evidence of lymph node metastases. Twenty patients were in TNM stage I, 1 in stage II, 1 in stage III, 1 in stage IVa, 2 in stage IVc, and 1 could not be staged due to lack of information on tumor size and lymph nodes (the AJCC Cancer Staging Manual, Sixth Edition (2002), Springer-Verlag New York). Following surgery, two patients were not given I-131 ablation therapy (one had microscopic unifocal PTC confined to the thyroid and one patient refused I-131). Twenty four patients received I-131 ablation therapy (median activity $147 \mathrm{mCi}$ (range 65299.7)). The stage I and II disease with uptake limited to the thyroid bed received I-131 activity of $100 \mathrm{mCi}$ or less, those with stage III or IV with thyroid bed uptake received activity of $100-150 \mathrm{mCi}$ when the uptake was limited to the thyroid bed and 150-200 $\mathrm{mCi}$ when there was an uptake outside the thyroid bed. One patient (Fig. 1) received large activity of $299.7 \mathrm{mCi}$ since the spinal metastasis was not taking up I-131 on DxWBS. During follow-up, six patients received additional therapies for persistent disease as follows: a second dose of I-131 therapy in two patients, a second dose of I-131 and additional surgeries in two patients, a second dose of I-131 and external beam radiotherapy in one patient and a second dose of I-131, surgery, and external beam radiotherapy in one patient. The primary tools that were used for the follow-up of these patients were the measurement of serum Tg (with concomitant measurement of anti-Tg antibodies) and DxWBS in addition to high-resolution ultrasonography. All patients except the two who did not receive I-131 had at least one follow-up withdrawal DxWBS with measurement of serum Tg. Discernable focal activity on the DxWBS with measurable uptake was considered positive. Lymph nodes that were oval in shape with fatty hila and no calcification or cystic formation were considered benign. In other situations, fine needle aspiration biopsy was done whenever feasible. The median follow-up period was 30 months (range, 10-48).

Fifteen patients $(57.7 \%)$ achieved complete remission defined as a negative clinical examination, negative DxWBS, and a Tg level $<2 \mathrm{ng} / \mathrm{dl}$ off thyroid hormone therapy (TSH $>30 \mathrm{mU} / \mathrm{l}$ ) with negative $\mathrm{Tg}$ autoantibodies 

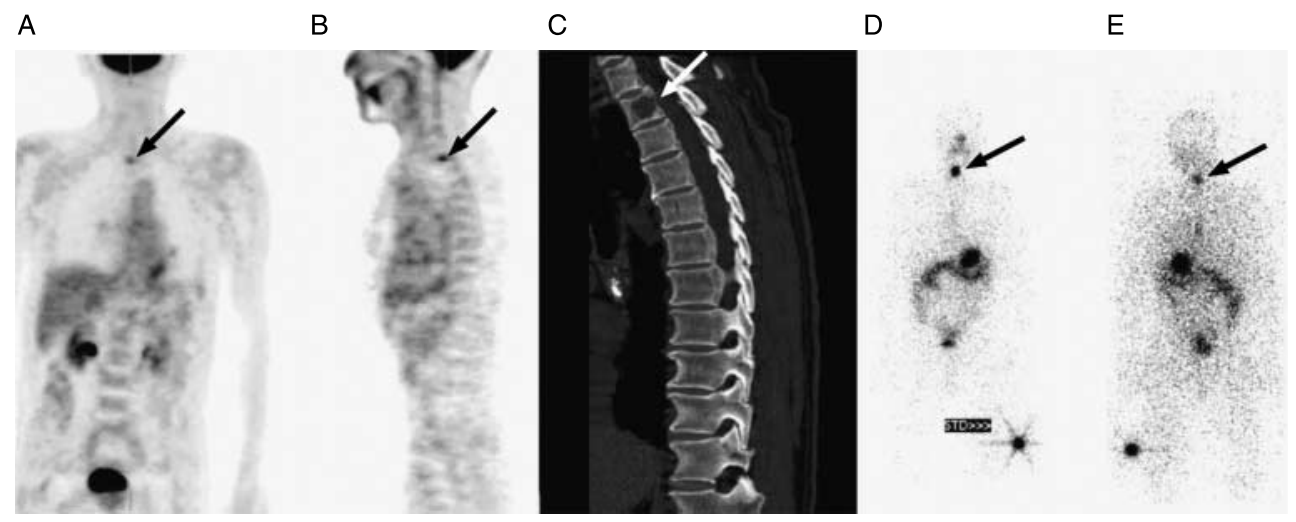

Figure 1 (A) Coronal and (B) sagittal views of the FDG-PET scan showing a hypermetabolic focus in the upper dorsal spine and another focus of less intensity at the left pericardial border. (C) A reconstruction CT scan of the dorsal spine shows a lytic lesion at T2 vertebral body. Biopsy of that lesion revealed metastatic papillary thyroid cancer. (D and E) The corresponding DxWBS shows an uptake limited to the thyroid bed only.

and negative ancillary imaging studies when done (high-resolution neck ultrasonography, CT scans of the neck and the chest, and FDG-PET scans). Nine patients $(34.6 \%)$ continued to have evidence of persistent disease (Tg $\geq 2 \mathrm{ng} / \mathrm{dl}$ off L-thyroxine, positive DxWBS, and/or positive fine needle aspiration biopsy of neck ultrasonographic findings) and two patients $(7.6 \%)$ had progression of the disease with development of new distant metastases.

\section{Pre-ablation (DxWBS) and post-ablation (TxWBS) whole body scanning}

Patients were kept off thyroid hormone therapy as described above. They were also prescribed a low-iodine diet for at least 1 week before scanning. Patients had not had any contrast-enhanced study for at least 3 months prior to DxWBS. At our institution, we routinely use $\mathrm{I}^{123}$ isotope for DxWBS and we have previously demonstrated its comparability to I-131 isotope (19). In all the 24 patients who underwent I-131 remnant ablation, TxWBS were similar to DxWBS without additional foci. Patients were given $10 \mathrm{mCi}$ of I-131 in the form of oral solution. Whole body scanning was done $24 \mathrm{~h}$ later using gamma camera. TxWBS was done 3-5 days after RAI ablation therapy. Planar whole body scans as well as dedicated films of the neck and chest regions were obtained for each patient.

\section{FDG-PET scanning}

All FDG-PET scans were performed while patients were off thyroid hormone therapy. Patients fasted for at least $8 \mathrm{~h}$ before scanning. Capillary blood sugar testing was done before scanning and patients with blood sugar $>8 \mathrm{mmol} / \mathrm{l}$ were excluded. Images were obtained with an ECAT EXACT camera (CTI, Knoxville, TN, USA) using a fullwidth at half-maximum of $4.5 \mathrm{~mm}$ and a transaxial field of view of $15 \mathrm{~cm}$. After i.v. administration of $10 \mathrm{mCi}$ $(370 \mathrm{MBq}) \mathrm{FDG}$, the patients were kept at rest in a quiet, dimly lit room for at least $40 \mathrm{~min}$. The patients were scanned while lying supine along the central axis of the PET table. Seven sequential emission images were obtained from the head to the upper thigh, requiring 56 min using a two-dimensional mode. Transmission scans were obtained with $68 \mathrm{Ge}$ rod sources for attenuation correction (3 min per bed position). The emission and transmission scans were obtained in an alternating sequence per bed position. Reconstruction of both the transmission and emission scans was performed using accelerated maximumlikelihood reconstruction and ordered subset expectation maximization (two iterations, eight subsets). Standardized uptake values (SUVs) were calculated as the ratio of the regional radioactivity concentration divided by the injected amount of radioactivity normalized to body weight. The average SUV in all the suspected lesions were measured with a region-of-interest technique.

The FDG-PET scans, DxWBS and TxWBS were interpreted independently and at different points in time by two trained qualified nuclear medicine radiologists (A R and A A). When disagreement arises, a review by a third nuclear medicine radiologist (M A) was obtained and a consensus was reached. The FDGPET scans were compared with DxWBS (and TxWBS in 24 patients) in terms of sites and number of foci of uptake and the concordance rate between scans was calculated.

\section{Statistical analysis}

Comparison of the FDG-PET scans with DxWBS was carried out in terms of the sites and number of foci of uptake. The $\chi^{2}$ test was used to compare the proportions of foci of uptake outside the thyroid bed between the two types of scans. The long-term outcome of those patients with positive FDG-PET scans was compared with the outcome of those patients with negative FDG-PET scans using Fisher's Exact test. $P<0.05$ was considered significant. 


\section{Results}

\section{Comparison of FDG-PET with DxWBS and $T x W B S$}

In all the 24 cases who received RAI ablation, the TxWBS were similar to DxWBS in terms of sites and number of lesions, though some lesions were better visualized on TxWBS. Therefore, the comparison of FDG-PET is the same for DxWBS and TxWBS. Of the 26 FDG-PET scans, 18 scans $(69.2 \%)$ were positive while 8 scans $(30.8 \%)$ were negative. A total of 40 foci were seen in the 18 positive FDG-PET scans (thyroid bed, 14; cervical lymph nodes, 15; lungs, 1; bone, 1; axillae, 7; and breast, 2). The median SUV was 3.7 (1.4-12.2). The corresponding DxWBS showed a total of 47 foci. The 24 TxWBS showed 45 lesions (each of the two patients who were not treated with RAI had one focus on DxWBS). In contrast to the uptake on FDG-PET that showed uptake of 26 foci ( $65 \%$ ) outside the thyroid bed, 45 foci $(95.7 \%)$ on DxWBS were in the thyroid bed while 2 foci $(4.3 \%)$ were in cervical lymph nodes and no focus was seen outside the neck area $(P=0.0000)$. Table 1 summarizes the sites of uptake by patients in the FDG-PET and the DxWBS scans.

Of the 26 FDG-PET and DxWBS scan pairs, only 3 pairs $(11.5 \%)$ were identical, showing the same foci in both sites. Two scan pairs $(7.7 \%)$ showed uptake in the same sites, but with more foci on DxWBS than on the FDG-PET scans. In seven scan pairs $(26.9 \%)$, the FDG-PET scans showed the same foci seen on DxWBS in addition to foci in other areas. In 14 cases $(53.9 \%)$, the scan pairs were completely discordant, showing foci in different locations.

\section{FDG-PET uptake outside the neck region}

Of the 26 patients studied, 4 patients (15.3\%) had FDG-PET uptake outside the neck region as follows: lungs and dorsal spine (1 patient; Fig. 1), breast (1 patient)

Table 1 Sites of uptake by patients in F-18-fluorodeoxyglucose position emission tomography (FDG-PET) and diagnostic whole body scanning (DxWBS) scan pairs done in 26 patients with differentiated thyroid cancer (DTC)

\begin{tabular}{lcc}
\hline Location & $\begin{array}{c}\text { FDG-PET (no. of } \\
\text { patients) }\end{array}$ & $\begin{array}{c}\text { DxWBS (no. of } \\
\text { patients) }\end{array}$ \\
\hline Thyroid bed alone & 8 & 22 \\
CLN alone & 4 & 2 \\
Thyroid bed and CLN & 2 & \\
Thyroid bed, CLN, & 1 & \\
and axilla & 1 & \\
CLN, lungs, and & & \\
bone & 1 & 2 \\
CLN and axilla & 1 & 26 \\
CLN and breasts & 8 & \\
Negative & 26 & \\
Total & & \\
\hline
\end{tabular}

CLN, cervical lymph nodes. and axillae ( 2 patients). Biopsies were obtained from one of the two patients with axillary uptake and showed granulomatous lymphadenitis; fungal and tuberculosis stains and cultures were negative (Fig. 2). In the second patient, biopsy was not done because the uptake was too faint (maximum SUV 1.4) and ultrasound of the axilla showed only small benign-looking lymph nodes. In the patient with breast uptake, fine needle aspiration biopsy of a corresponding $1.5 \mathrm{~cm}$ nodule seen on ultrasonography showed that only fat necrosis and mammography was negative. In contrast, the patient with lung and dorsal spine uptake underwent biopsy of a dorsal spine vertebra and that confirmed the presence of metastatic papillary thyroid cancer (Fig. 1).

\section{Prognostic value of the FDG-PET scans}

The FDG-PET scans were more likely to be positive in higher stage disease; of the 18 cases with positive FDGPET, 13 were in stage I, one in stage II, one in stage III, one in stage IVa, and two in stage IVc. In contrast, all eight cases with negative FDG-PET scans were in stage 1 except one patient who could not be staged due to lack of information. Furthermore, patients with negative FDG-PET were more likely to achieve remission than those with positive FDG-PET scans; over a median follow-up period of 30 months (range 10-48), only 8 out of 18 patients $(44.4 \%)$ with positive FDG-PET were in remission while 8 patients $(44.4 \%)$ had evidence of persistent disease and 2 patients (11.2\%) had progression of their disease (Table 2). The median $\mathrm{Tg}$ level in those with persistent disease was $21 \mathrm{ng} / \mathrm{ml}$ (range 13.3-167 $\mathrm{ng} / \mathrm{ml}$ ) and in those with progression, Tg was $734 \mathrm{ng} / \mathrm{ml}$ and $>5000 \mathrm{ng} / \mathrm{ml}$. In contrast, seven out of eight cases $(87.5 \%)$ with negative FDG-PET scans were in remission ( $\mathrm{Tg} 0-1.4 \mathrm{ng} / \mathrm{ml}$ with negative imaging studies) and only one case had persistent disease with $\mathrm{Tg}$ of $16.7 \mathrm{ng} / \mathrm{ml}(P=0.04)$.

\section{Discussion}

In this study, we investigated the potential role of FDG-PET scanning in the initial evaluation of patients with DTC. Our motive was the fact that aggressive forms of thyroid cancer are more likely to metastasize and at the same time to be more metabolically active and therefore to take up FDG and be seen on FDG-PET whole body scanning $(16-18,20)$. On the other hand, cells of high-grade tumors usually lose some of their differentiated functions such as uptake of iodine and therefore are likely to be missed on DxWBS and TxWBS (16). In that respect, FDG-PET could play an important role in the staging of aggressive DTC and may affect the choice and intensity of management options. For example, disclosure of a distant metastasis that may have been missed on the conventional RAI whole body scan may indicate the need for surgical removal if feasible, or administration of external 
A

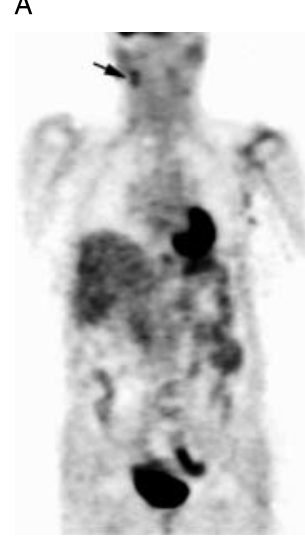

B

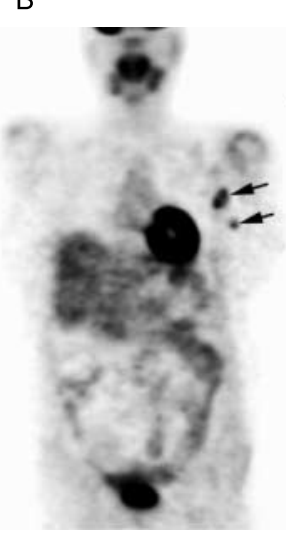

C

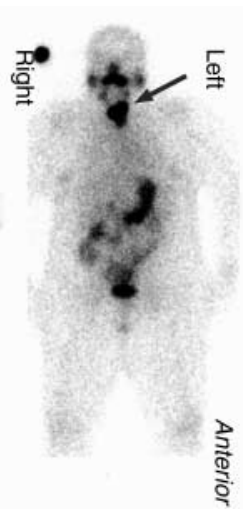

D

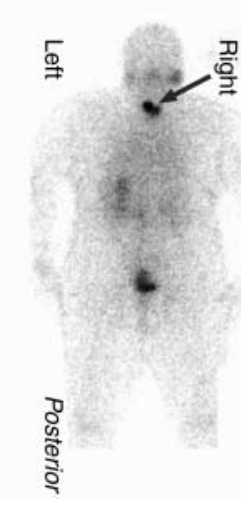

Figure 2 (A) FDG-PET whole body scan shows two hypermetabolic foci in the right upper neck (arrows). FNA of cervical lymph nodes at this site revealed metastatic PTC. There is also another focus of less intensity in the left mid-neck and three additional foci of uptake in the left axilla (arrows), better seen on (B).

Excision biopsy of a left axillary lymph node revealed a necrotizing granuloma without evidence of malignancy. ( $\mathrm{C}$ and D). The corresponding DxWBS shows a significant uptake limited to the thyroid bed area. beam radiotherapy or higher doses of RAI. In contrast to DxWBS and TxWBS, which were mostly positive in the thyroid bed area, we have demonstrated that the FDG-PET scans were more likely to reveal foci of uptake in locations outside the thyroid bed. While most of the foci were in cervical lymph nodes, FDG-PET also showed foci outside the neck area including lungs, bone, mediastinum, and others. Some of these foci could be false positive uptake as demonstrated in some cases; in some other cases, FDG-PET was crucial in demonstrating metastatic disease. For example, in one patient with a high-grade tumor, the DxWBS and the TxWBS revealed an uptake that was limited to the thyroid bed while FDG-PET revealed a significant focus in the dorsal vertebrae, the biopsy of which confirmed metastatic papillary thyroid cancer (Fig. 1). Previous studies have rarely assessed the role of FDG-PET scanning in the early evaluation of the disease. The majority of studies focused on its role in the follow-up of patients suspected to have recurrent or persistent disease in whom one or more findings indicate the presence of the disease but its exact location or extent are not clear. It has been shown to be most consistently useful in cases of high Tg and negative DxWBS in which the FDG-PET scans have a sensitivity of about $47-100 \%$ and a specificity of $25-95 \%(7,8)$. While serum $\mathrm{Tg}$ and DxWBS are excellent tools for follow-up of patients who were treated by surgery and I-131 in the past, they have a limited role in the postoperative period before I-131 ablation. The potential role of FDG-PET, if confirmed in

Table 2 The long-term outcome of 26 differentiated thyroid cancer (DTC) patients based on the results of F-18-fluorodeoxyglucose position emission tomography (FDG-PET) scanning at the postoperative evaluation.

\begin{tabular}{lcccc}
\hline & Remission & $\begin{array}{c}\text { Persis- } \\
\text { tence }\end{array}$ & $\begin{array}{c}\text { Pro- } \\
\text { gression }\end{array}$ & Total \\
\hline FDG-PET & & & & \\
Positive & 8 & 8 & 2 & 18 \\
Negative & 7 & 1 & 0 & 8 \\
Total & 15 & 9 & 2 & 26 \\
\hline
\end{tabular}

future studies, could be of significant help in defining the extent of the disease at this stage with potential implications on the management.

Only a few studies have investigated the role of FDGPET scanning in patients who had not yet received RAI. These studies, however, had different aims from our study. A recent study compared the diagnostic accuracy of fused FDG-PET/CT scans with neck ultrasonography and contrast-enhanced CT scans of the head and neck area in defining cervical lymph nodes with metastases in newly diagnosed DTC patients who have not yet undergone any thyroid surgery (21). It was found to be comparable with these two imaging modalities in all level cervical lymph nodes and also in the lateral cervical lymph nodes (21). This study did not comment on FDG uptake outside the neck area. Another study assessed the value of FDG-PET scanning in thyroid nodules with inconclusive fine needle aspiration (FNA) biopsy and showed that FDG-PET was positive in all cases of malignancy with a negative predictive value of $100 \%$ but was also positive in 34\% of benign nodules (22). In that study, FDG-PET decreased the number of unnecessary hemithyroidectomies for inconclusive FNA by $66 \%$ (22). In another study, FDG-PET was assessed as a preoperative evaluation tool for patients with thyroid nodules; in 31 patients with 48 lesions, it was found that 9 out of 15 malignant lesions were FDG-avid while 30 out of 33 benign lesions were FDG-cold giving positive and negative predictive values of 75 and $83 \%$ respectively (23). A few other studies assessed the prevalence of thyroid cancer in thyroid incidentalomas detected by the FDG-PET scans done for other purposes and found an overall prevalence of incidentalomas of about $1.2-2.2 \%$ with a relatively high malignancy rate of $14-50 \%(24-27)$.

The prognostic value of FDG-PET scans in thyroid cancer has been demonstrated in patients who were treated in the past $(17,18)$. Our study suggests that FDG-PET could be of prognostic value in the initial evaluation of patients with DTC. This is demonstrated by the fact that the majority of cases with high-grade 
malignancy were FDG-PET positive, while the vast majority of patients with negative scans were in stage 1 disease. Furthermore, a larger percentage of patients with persistent or progressive disease were FDG-PET positive, while most of those with negative FDG-PET scans achieved remission. Robbins et al. retrospectively studied 400 patients who were treated in the past with surgery and RAI and found a high correlation between survival and the results of FDG-PET in these patients. In a multivariate analysis - among multiple prognostic factors including age, initial stage, histology, Tg, RAI, and FDG-PET results - only age and FDG-PET results continued to be strong predictors of survival. Furthermore, the most active lesions and the number of lesions of FDG-PET scanning inversely correlated with survival (17). Some studies evaluated FDG-PET in the more aggressive forms of DTC such as hurthle cell and insular subtypes and found high positive rates in these tumors consistent with their high-grade malignancy and poor prognosis (28-30). If the prognostic value of FDG-PET at the postoperative evaluation is confirmed in larger studies, it could add a more objective tool than the currently widely used clinicopathological staging systems which have their limitations in clinical practice.

Our study has some limitations. Due to ethical reasons, the findings on the FDG-PET scans could not be always confirmed by the fine needle biopsy or histopathological examination except when indicated, such as in the case described in Fig. 1. However, the foci on FDG-PET were confirmed by at least two independent reviewers and the SUV values were significantly high. Moreover, 16 out of the 18 patients with positive FDGPET scans had lymph node metastases on the original surgery. This suggests that the findings on the FDG-PET scans in the neck area are related to additional lymph nodes metastases that were not resected. The rate of lymph node metastases is variable and the high rate in our study may have contributed to the high rate of positive FDG-PET uptake in the neck region. Another shortcoming of our study is the relatively short followup duration. DTC is generally a malignancy with excellent prognosis but with significant long-term recurrence rate. The prognostic value of FDG-PET scanning in this relatively short period of follow-up may change over time. The study showed that FDG-PET revealed more foci of uptake outside the thyroid bed, presumably lymph node metastases. In that respect, it may have an implication on the staging of the disease especially in patients older than 45 years and also on the I-131 ablation activity. However, in our study, FDGPET was of no significant help in revealing distant metastases except in one patient (Fig. 1). This might be due to the small sample size and the low rate of distant metastases at the initial presentation. In this study, our patients were relatively young; however, their disease tended to be more aggressive with high rate of lymph node metastases and extrathyroidal extension. This may have contributed to the high positive rate of the
FDG-PET scan in this group of patients. Another point to mention is that our study was done with conventional FDG-PET scanning; fused CT-PET scanning is emerging as a standard technique for the FDG-PET scanning and its use may have added positively to the findings in this study.

In conclusion, our study demonstrates that FDG-PET is more likely to disclose locoregional or distant foci in DTC than DxWBS and TxWBS. Our study, however, does not conclusively indicate that these foci are always related to presence of malignant disease since there is no histopathological confirmation. However, the high median SUVs and the correlation between positive FDG-PET scans and long-term course of the disease suggest that in the vast majority of these cases, the FDGPET foci represented real foci of the disease. Our study calls for further exploration of the potential role of FDGPET in the initial evaluation of DTC. If our findings are confirmed in future studies, FDG-PET may help define the extent of the disease more accurately with subsequent institution of appropriate therapy. In this respect, it has the potential role of being an important objective staging tool. FDG-PET also seems to have an important prognostic value when used in the initial evaluation of patients with DTC.

\section{Acknowledgements}

The authors would like to thank $\mathrm{Mr}$ Nasser $\mathrm{Al}$ Habashnah, RN for his excellent help in scheduling patients and maintaining data, and Mr Mohamed Al Rwaily from Radiology Department for technical help. There is no external source of funding involved in this project. We would like also to acknowledge the support of the departments of Medicine, Radiology, and Research center. The authors declare that there is no conflict of interest in the research presented in this article that would potentially prejudice its impartiality.

\section{References}

1 Jemal A, Siegel R, Ward E, Murray T, Xu J, Smigal C \& Thun MJ. Cancer statistics. CA: A Cancer Journal for Clinicians $2006 \mathbf{5 6}$ 106-130.

2 Davies L \& Welch HG. Increasing incidence of thyroid cancer in the United States, 1973-2002. Journal of the American Medical Association $20062952164-2167$.

3 Singer PA, Cooper DS, Daniels GH, Ladenson PW, Greenspan FS, Levy EG, Braverman LE, Clark OH, McDougall IR, Ain KV \& Dorfman SG. Treatment guidelines for patients with thyroid nodules and well-differentiated thyroid cancer. American Thyroid Association. Archives of Internal Medicine 1996156 2165-2172.

4 Cooper DS, Doherty GM, Haugen BR, Kloos RT, Lee SL, Mandel SJ, Mazzaferri EL, McIver B, Sherman SI \& Tuttle RM. Management guidelines for patients with thyroid nodules and differentiated thyroid cancer. Thyroid $2006 \mathbf{1 6} 109-142$. 
5 Mazzaferri EL \& Kloos RT. Clinical review 128: current approaches to primary therapy for papillary and follicular thyroid cancer. Journal of Clinical Endocrinology and Metabolism 200186 1447-1463.

6 Mazzaferri EL \& Jhiang SM. Long-term impact of initial surgical and medical therapy on papillary and follicular thyroid cancer. American Journal of Medicine 199497 418-428.

7 Stokkel MP, Duchateau CS \& Dragoiescu C. The value of FDG-PET in the follow-up of differentiated thyroid cancer: a review of the literature. Quarterly Journal of Nuclear Medicine and Molecular Imaging $2006 \mathbf{5 0} 78-87$.

8 Hooft L, Hoekstra OS, Deville W, Lips P, Teule GJ, Boers M \& van Tulder MW. Diagnostic accuracy of 18F-fluorodeoxyglucose positron emission tomography in the follow-up of papillary or follicular thyroid cancer. Journal of Clinical Endocrinology and Metabolism 200186 3779-3786.

9 Alnafisi NS, Driedger AA, Coates G, Moote DJ \& Raphael SJ. FDGPET of recurrent or metastatic 131I-negative papillary thyroid carcinoma. Journal of Nuclear Medicine 200041 1010-1015.

10 Alzahrani AS, Mohamed GE, Al Rifai A, Al-Sugair A, Abdel Salam SA, Sulaiman OM \& Demirkaya O. Role of [18F]fluorodeoxyglucose positron emission tomography in follow-up of differentiated thyroid cancer. Endocrine Practice 200612 152-158.

11 Conti PS, Durski JM, Bacqai F, Grafton ST \& Singer PA. Imaging of locally recurrent and metastatic thyroid cancer with positron emission tomography. Thyroid 19999 797-804.

12 Dietlein M, Scheidhauer K, Voth E, Theissen P \& Schicha H. Fluorine-18 fluorodeoxyglucose positron emission tomography and iodine-131 whole-body scintigraphy in the follow-up of differentiated thyroid cancer. European Journal of Nuclear Medicine $1997241342-1348$.

13 Dietlein M, Scheidhauer K, Voth E, Theissen P \& Schicha H. Follow-up of differentiated thyroid cancer: what is the value of FDG and sestamibi in the diagnostic algorithm? Nuklearmedizin 1998 37 12-17.

14 Grunwald F, Schomburg A, Bender H, Klemm E, Menzel C, Bultmann T, Palmedo H, Ruhlmann J, Kozak B \& Biersack HJ. Fluorine-18 fluorodeoxyglucose positron emission tomography in the follow-up of differentiated thyroid cancer. European Journal of Nuclear Medicine 199623 312-319.

15 Helal BO, Merlet P, Toubert ME, Franc B, Schvartz C, GauthierKoelesnikov H, Prigent A \& Syrota A. Clinical impact of (18)F-FDGPET in thyroid carcinoma patients with elevated thyroglobulin levels and negative (131)I scanning results after therapy. Journal of Nuclear Medicine 200142 1464-1469.

16 AL-Nahhas A. Dedifferentiated thyroid carcinoma: the imaging role of 18F-FDG-PET and non-iodine radiopharmaceuticals. Nuclear Medicine Communications 200425 891-895.

17 Robbins RJ, Wan Q, Grewal RK, Reibke R, Gonen M, Strauss HW, Tuttle RM, Drucker W \& Larson SM. Real-time prognosis for metastatic thyroid carcinoma based on 2-[ $\left.{ }^{18} \mathrm{~F}\right]$ fluoro-2-deoxy-Dglucose-positron emission tomography scanning. Journal of Clinical Endocrinology and Metabolism 200691 498-505.

18 Wang W, Larson SM, Fazzari M, Tickoo SK, Kolbert K, Sgouros G, Yeung H, Macapinlac H, Rosai J \& Robbins RJ. Prognostic value of [18F]fluorodeoxyglucose positron emission tomographic scanning in patients with thyroid cancer. Journal of Clinical Endocrinology and Metabolism 200085 1107-1113.
19 Alzahrani AS, Bakheet S, Al Mandil M, Al-Hajjaj A, Almahfouz A \& Al Haj A. 123I isotope as a diagnostic agent in the follow-up of patients with differentiated thyroid cancer: comparison with post 131 I therapy whole body scanning. Journal of Clinical Endocrinology and Metabolism $2001865294-5300$.

20 Wang W, Larson SM, Tuttle RM, Kalaigian H, Kolbert K, Sonenberg M \& Robbins RJ. Resistance of [18f]-fluorodeoxyglucose-avid metastatic thyroid cancer lesions to treatment with high-dose radioactive iodine. Thyroid 2001 11 1169-1175.

21 Jeong HS, Baek CH, Son YI, Choi JY, Kim HJ, Ko YH, Chung JH \& Baek HJ. Integrated 18F-FDG-PET/CT for the initial evaluation of cervical node level of patients with papillary thyroid carcinoma: comparison with ultrasound and contrast-enhanced CT. Clinical Endocrinology $2006 \mathbf{6 5} 402-407$.

22 de Geus-Oei LF, Pieters GF, Bonenkamp JJ, Mudde AH, BleekerRovers CP, Corstens FH \& Oyen WJ. 18F-FDG-PET reduces unnecessary hemithyroidectomies for thyroid nodules with inconclusive cytologic results. Journal of Nuclear Medicine 2006 47 770-775.

23 Mitchell JC, Grant F, Evenson AR, Parker JA, Hasselgren PO \& Parangi S. Preoperative evaluation of thyroid nodules with 18FDG-PET/CT. Surgery 2005138 1166-1174.

24 Kang KW, Kim SK, Kang HS, Lee ES, Sim JS, Lee IG, Jeong SY \& Kim SW. Prevalence and risk of cancer of focal thyroid incidentaloma identified by $18 \mathrm{~F}$-fluorodeoxyglucose positron emission tomography for metastasis evaluation and cancer screening in healthy subjects. Journal of Clinical Endocrinology and Metabolism $2003 \mathbf{8 8} 4100-4104$.

25 Chu QD, Connor MS, Lilien DL, Johnson LW, Turnage RH \& Li BD. Positron emission tomography (PET) positive thyroid incidentaloma: the risk of malignancy observed in a tertiary referral center. American Surgeon 200672 272-275.

26 Kim TY, Kim WB, Ryu JS, Gong G, Hong SJ \& Shong YK. 18Ffluorodeoxyglucose uptake in thyroid from positron emission tomogram (PET) for evaluation in cancer patients: high prevalence of malignancy in thyroid PET incidentaloma. Laryngoscope $20051151074-1078$.

27 Van den Bruel A, Maes A, De Potter T, Mortelmans L, Drijkoningen M, Van Damme B, Delaere P \& Bouillon R. Clinical relevance of thyroid fluorodeoxyglucose-whole body positron emission tomography incidentaloma. Journal of Clinical Endocrinology and Metabolism 200287 1517-1520.

28 Pryma DA, Schoder H, Gonen M, Robbins RJ, Larson SM \& Yeung HW. Diagnostic accuracy and prognostic value of 18F-FDGPET in Hurthle cell thyroid cancer patients. Journal of Nuclear Medicine 200647 1260-1266.

29 Diehl M, Graichen S, Menzel C, Lindhorst E \& Grunwald F. F-18 FDG-PET in insular thyroid cancer. Clinical Nuclear Medicine 2003 28 728-731.

30 Lowe VJ, Mullan BP, Hay ID, McIver B \& Kasperbauer JL. 18F-FDGPET of patients with Hurthle cell carcinoma. Journal of Nuclear Medicine $2003 \mathbf{4 4} 1402-1406$.

Received 28 December 2007

Accepted 26 January 2008 